(a) (1) https://creativecommons.org/licenses/by/4.0/

ARTIGO

\title{
A FOTOGRAFIA AGENCIANDO LINHAS DE VIDA NOS COTIDIANOS ESCOLARES
}

\author{
JANETE MAGALHÃES CARVALHO ${ }^{1}$ \\ ORCID: https://orcid.org/0000-0001-9906-2911 \\ STEFERSON ZANONI ROSEIRO ${ }^{2}$ \\ ORCID: https://orcid.org/0000-0003-1424-2281 \\ SUZANY GOULART LOURENÇO ${ }^{3}$ \\ ORCID: https://orcid.org/0000-0002-4404-772X
}

\begin{abstract}
RESUMO: O artigo objetiva pensar com crianças, junto a fotografias, a vida que insiste em transbordar em meio às vivências em uma escola pública de ensino fundamental. Diante do ataque capitalístico que sofrem os corpos em um cenário em que a vida é radicalmente empobrecida, discute a possibilidade de uma leitura fotográfica ao inverso dessa força de contenção, acreditando que a vida e a resistência antecedem as tentativas de controle. Utiliza como abordagem metodológica as redes de conversações com crianças, disparadas por fotografias, entendendo que a fotografia produz e força o deslocamento de pensamentos e encontros, pois cria superfícies vibráteis, produz reencontros de tempos e espaços, reinventa o passado e ilumina o presente, podendo suscitar uma potência e uma multiplicidade de criação de sentidos que vivem e morrem entre a intenção do fotógrafo e a imprevisibilidade-impossibilidade de uma única visão da fotografia. Conclui que as crianças buscam expressar linhas de vida que pulsam na relação de seus corpos com outros corpos e incorpóreos em seus cotidianos como um impulso para o movimento de criação.
\end{abstract}

Palavras-chave: Fotografia, Linhas de vida, Redes de conversações, Cotidianos escolares, Apego à vida.

\section{THE PHOTOGRAPH ASSEMBLING LIFELINES IN DAILY LIFE AT SCHOOL}

\begin{abstract}
The paper aims to think with children, close to photographs, the life that insists on overflowing amidst the experiences in a public elementary school. Facing the capitalistic attack on bodies in a scenario in which the life is radically impoverished, it discusses the possibility of a photographic reading in the inverse of this force of containment, believing that life and resistance precede attempts of control. It uses as a methodological approach conversation networks with children, triggered by photographs, understanding that the photograph produces and forces the displacement of thoughts and encounters, as it creates vibrating surfaces, produces reunions of times and spaces, recreates the past and illuminates the present, being able to raise a power and a multiplicity of creation of meanings that live and die between the intention of the photographer and the unpredictability-impossibility of a single vision of the photograph. It concludes that children seek to express lifelines that pulsate in the relation of their bodies with other bodies and incorporeal in their daily life as an impulse for the creative movement.
\end{abstract}

\footnotetext{
${ }^{1}$ Universidade Federal do Espírito Santo. Vitória, ES, Brasil. <janetemc@terra.com.br>

2 Universidade Federal do Espírito Santo. Viana, ES, Brasil.<zanoniroseiro@gmail.com>

${ }^{3}$ Universidade de Vila Velha. Vitória, ES, Brasil. <suzany.goulart@gmail.com> Educação em Revista|Belo Horizonte|v.36|e231322|2020
} 
Keywords: Photograph, Lifelines, Conversation networks, Daily life at school, Attachment to life.

\section{LA FOTOGRAFÍA ENSAMBLANDO LÍNEAS DE VIDA EN LA VIDA DIARIA EN LA ESCUELA}

RESÚMEN: El artículo tiene como objetivo pensar con los niños, junto con fotografias, la vida que insiste en desdobrarse en medio de las experiencias en una escuela primaria pública. Ante el ataque capitalista sufrido por los cuerpos en un escenario en el que la vida se empobrece radicalmente, analiza la posibilidad de una lectura fotográfica del opuesto de esta fuerza de restricción, creyendo que la vida y la resistencia precede a los intentos de control. Utiliza como enfoque metodológico las redes de conversaciones com niños, desencadenadas por fotografias, entendiendo que la fotografia produce y fuerza el desplazamiento de pensamientos y encuentros, ya que crea superficies vibratorias, produce reuniones de tiempos y espacios, reinventa el passado y ilumina el presente. Puede dar lugar a un poder y una multiplicidad de sentido que viven y mueren entre la intención del fotógrafo y la imprevisibilidadimposibilidad de una visión única de la fotografia. Concluye que los niños buscan expressar líneas de vida que pulsan en la relación de sus cuerpos com otros cuerpos e incorporales em sus vidas cotidianas en la escuela como un impulso para el movimiento creativo.

Palabras clave: Fotografías, Líneas de vida, Redes de conversaciones, Cotidiano de la escuela.

\section{INTRODUÇÃO}

\section{A fotografia como vetor de expansão de linhas de vida nos cotidianos escolares}

É comum relacionarmos imagens de vida e de morte com nossas vidas. De modo geral, as imagens possuem a potência não só de ficcionar o tempo como também de abrir a percepção para a existência de outras experiências e de outros mundos. A fotografia, como a ficção científica, cria possibilidades de pensarmos outros mundos a partir do mais prosaico do cotidiano. Outros mundos são montados e desmontados, fabricados, recortados, enquadrados e desenquadrados por meio da fotografia. Álbuns de família, retratos dos filhos, fotos escolares, imagens de férias - toda uma maquinaria que transpassa, perfura, invade e, antes de especular ou encerrar um real, produz-cria-fabrica mundos, memórias e vidas. Chocamo-nos diante de imagens, choramos, entristecemo-nos, mas também sorrimos, alegramo-nos e nos fortalecemos e, decerto, nunca sabemos como exatamente reagiremos diante de uma imagem.

A imagem funciona de modo inesperado, produz em nós afetos de forma imprecisa. É possível que reajamos a uma mesma imagem ora de um jeito, outra d'outro, e toda a vida produzida a partir desses dois momentos divergiriam drasticamente. Diante do mundo imagético em que vivemos, onde toda e qualquer imagem circula pelo ar e se materializa em nossas mãos, é possível dizer que a fotografia cumpre essa função da imagem, hoje, permitindo a vivência de uma microexperiência (WUNDER, 2010) de vida e de morte.

Deleuze (1992) argumenta que o sistema capitalista atual se caracteriza como flexível, volátil, muito mais voltado para a sobreprodução que para a produção e a criação. Nesse sentido, os processos de subjetivação apontariam uma modelização de comportamentos, sensibilidade, percepção, memória, relações etc. Se Foucault (2014) falava que a escola compunha um dispositivo do poder disciplinador, isto é, organizava-se como uma instituição capaz de docilizar corpos utilizando técnicas e comportamentos ensinados para se produzir o corpo desejável à sociedade, hoje vemos não apenas a produção de corpos como também a produção de afetos e paixões que devem ser produzidos para fazer prevalecer o modo de vida que alimenta o agenciamento do Capital. Nesse direcionamento, a produção da subjetividade estaria no campo do que é administrável pelo capitalismo hoje, ou seja, os processos de 
produção articulados aos indivíduos e grupos na sua maneira de estar no mundo: uma subjetividade modelada, recebida, consumida.

Em outras palavras, travamos, hoje, uma guerra imagética. Se, conforme diziam Foucault (2015) e o grupo anônimo que publicou a revista Tiqqun (2019), testemunhávamos uma nova modalidade da guerra civil, hoje essa guerra ocorre também no campo do imaginário, na própria produção de imagens de vida que fazemos. Há um conjunto de subjetividades serializadas que compõem os mecanismos harmonizados com os ideais do Capital, distribuídos em quase todos os cenários da vida. São subjetividades industriais, econômicas, competitivas e empreendedoras que agenciam todo um conjunto de condições de sobrevivência do capitalismo e destruição do mundo, visto que as forças que administram o capitalismo concebem a subjetividade como mais importante do que qualquer outro tipo de produção, pois se trata de fazer viver e de fazer morrer.

Essa maneira de perceber o mundo que invade a existência do homem chega pela linguagem, pela família e pelos equipamentos que estão à sua volta. Não há como separar relações de produção econômica das relações de produção de subjetividade. Nessa perspectiva, a noção de sujeito é substituída por agenciamento coletivo de enunciação, ou seja, toda a produção de sentido não está centrada em agentes individuais. Há, no lugar, processos descentrados de apropriações, de signos heterogêneos que estão em escala extrapessoal (mídia, ecologia, economia) e em escala infra-humana (afeto, desejo, imagens) (LAZZARATO, 2014). A subjetivação incide em um descentramento que se faz e se perfaz nos processos de produção social e material. Desse modo, apesar de experimentarmos agenciamentos cuja lógica é a modelização das subjetividades, nossas apostas entram em relação com as possibilidades de aberturas aos processos de subjetivação singularizantes que expandem as forças ativas da vida e abrem fissuras ou mesmo destronam as estratificações dogmáticas.

Assim, propomos nos aliançar às crianças e pensar, junto às fotografias, a vida que insiste em transbordar em meio às aprendências inventadas na escola pública. Se concordamos com a premissa deleuziana de um forte ataque capitalístico às vidas produzidas nos corpos, isto é, na produção de subjetividades, pensamos ser também possível fazer uma leitura fotográfica do inverso dessas forças de contenção. A quantidade de imagens que produzem o modo de ser necessário ao capitalismo é inegavelmente fácil de encontrar; todavia, acreditando na aposta ética negriana de que a vida e a resistência antecedem as tentativas de controle, pensamos ser também possível dizer isso para a produção imagética do mundo, para as fotografias que espalham vida. A fuga aos padrões universalizantes de modelização relaciona-se com a abertura para a vida, para o engendramento de linhas de singularização da vida em contraposição às linhas de sujeição e morte.

Nossa proposta coloca-se, então, como abertura ao trabalho com imagens na produção dessa vida fugidia. Diante de um cenário em que a vida é radicalmente empobrecida, perguntamo-nos como manter a vida e dar a ela sentidos que extrapolem as paixões tristes e empobrecidas que tentam nos arrastar. É uma questão bergson-nietzschiana: o que nos resta, então, da vontade de vida? Diante dos cenários de atrocidades contra a educação, contra professoras e professores, contra a escola, as crianças e a própria vida, como nos posicionamos? Como lutamos? Com quais armas temos proximidade? Com a arma que dizima o outro ou com as armas que nos aproximam uns dos outros? De que modos enfrentamos o poder sobre a vida? Quanto de apego à vida ainda nutrimos?

Inspirados pelas fotografias de Reg Speller - fotógrafo que viveu em algum momento do século XX e que circulou por parte do hemisfério norte com sua câmera -, colocamo-nos em contato com as crianças de uma escola pública da rede de Cariacica/ES para conversar sobre as possibilidades de apego à vida. ${ }^{4}$ As conversas com as fotografias foram gravadas e transcritas. Ao longo do texto, elas aparecerão em itálico e com espaço simples, sem nenhum tipo de identificação ou diferenciação dos participantes. Em todos os momentos, as conversas ocorreram em múltiplas vozes, típico de um trabalho

\footnotetext{
${ }^{4} \mathrm{Em}$ As duas fontes da moral e da religião, Henri Bergson (1978) conceitua como apego à vida os modos como experimentamos a própria vida para além da inteligência, por meio das ideias de "todo da obrigação", da "função de fabulação" e da "emoção criadora". David Lapoujade (2017) nos afirma que é com esta última força que temos um novo modo de confiança, pelo qual experimentamos a vida a partir de nossa potência criadora. Um salto intensivo é dado, frisa o autor, saímos de nossas montagens sensório-motoras, do nosso apego às formas, para nos apegarmos aos movimentos, aos fluxos, à possibilidade de proliferação de mundos.
} 
em sala de aula. É também preciso destacar que optamos por não recuar as cenas ou reduzir a fonte ao apresentarmos as conversas, de modo a dar maior visibilidade a seu texto, apostando eticamente em sua possibilidade de leitura em igual peso com o texto acadêmico.

Assim, olhamos para as fotografias - todas em preto e branco - e perguntamos pelas possibilidades de vida que os corpos ali assumiam, pelo colorido de vida que poderiam nos suscitar. Em dado momento, perguntamos: "O que essas fotos têm em comum?". As respostas são muitas: as cores, pessoas, crianças, lugares bonitos, lugares 'antigos', e por aí vai. Até que, em dado momento, uma criança fala, em tom bem baixo, sobre algo que lhe escapa dos lábios.

“Tem riso?", pergunta. O impacto é rápido, inesperado e, todavia, certeiro.

Ali, diante de fotografias muito anteriores ao tempo daquelas crianças, começávamos a indagar pelo apego à vida que aqueles corpos - corpos-crianças - conseguiam carregar em imagens. Apego à vida que nos desloca dos automatismos e nos convoca a nos apegarmos às forças, não às formas (LAPOUJADE, 2017). Indagávamos, em miúdos, pela dança da vida que faz o cansaço titubear.

\section{ENTRE AS LINHAS... AS IMAGENS FOTOGRÁFICAS}

Uma escola é povoada de imagens. Imagens de professoras e professores em reunião, alunos fofocando, alunas jogando futebol, famílias brigando, refeitórios cheios, ventiladores barulhentos. Mas não apenas as imagens imediatas povoam as escolas, também nosso imaginário delas. Uma criança sentada em uma cadeira pode tanto ser a imagem dela mesma - comportada, bagunceira, tagarela, de castigo, compenetrada - quanto trazer, junto dela, outras imagens que lhe invadem o pensamento, o corpo, os cadernos, livros e todas as outras materialidades que ela consegue tocar.

Cada corpo numa escola carrega em si diferentes planos de composição, afeta o mundo em todas as suas ações, superfícies e relações e, com isso, produz um emaranhado de possibilidades imagéticas.

Assim sendo, temos que estar atentos, pois, como afirma Mia Couto (2014, p.47),

$\mathrm{Na}$ vida tudo chega de súbito. O resto, o que desperta tranquilo, é aquilo que, sem darmos conta, já tinha acontecido. Uns deixam a acontecência emergir, sem medo. Esses são os vivos. Os outros se vão adiando. Sorte a destes últimos se vão a tempo de ressuscitar antes de morrerem.

Gilles Deleuze e Claire Parnet (2004) dizem que, no mundo, existem linhas que se cruzam e se cortam sobre e sob todas as coisas. As imagens que fazemos do mundo são atravessadas por essas linhas que ora são latentes em criação, ora são demasiado controladoras. Haveria linhas duras correspondentes a uma segmentaridade, referentes aos papéis modelados, como família, profissão, consumo etc. Segmentos bem determinados, em todas as direções, que nos enquadrariam em todos os sentidos como "pacotes de linhas segmentarizadas" (DELEUZE; PARNET, 2004, p. 145). Juntamente com essas linhas duras, temos linhas moleculares, bem mais flexíveis, que nos atravessariam não apenas como indivíduos, mas como sociedade e grupos.

Segundo Deleuze e Parnet (2004), sob essa segunda espécie de linhas, de fluxos moleculares, se passariam devires, microdevires, que nos conduziriam através dos segmentos, mas também através dos nossos limiares, numa direção não preexistente ou previsível - seriam as linhas de fuga.

A linha segmentarizada marca ou pode marcar um corte, mas existem, recortando essas linhas, as fissuras, que não coincidem com as linhas de grandes cortes segmentários. Tais fissuras acontecem sobre uma linha marcando um limiar de diminuição de resistência ou um aumento de um limiar de exigência, provocando fluxos em movimento. As linhas flexíveis, no entanto, não são mais pessoais, mais íntimas, pois as "microfissuras" são coletivas, não mais e nem menos como os macrocortes também são pessoais. As linhas de fuga seriam as de ruptura, como uma "dobra" ou um puro movimento difícil de ser descoberto, que toma as coisas pelo meio e está sempre no meio - no meio das outras espécies de linhas. 
Nesse contexto, foi considerando que a produção de subjetividades se dá de modo cambiante (Gallo, 2010), tal como o atravessamento das linhas de segmentaridade dura, flexíveis e de fuga nos agenciamentos que compõem esta produção em que nos encontramos com as crianças de uma escola pública municipal de Cariacica/ES. Nesses encontros, com-versamos, versamos com as crianças sobre as possibilidades de o apego à vida se potencializar diante das tentativas de estratificação da vida.

A primeira fotografia é mostrada e, de imediato, as crianças entram em certa euforia, rindo da cena que é mostrada, das bundas despidas, das crianças encurraladas.

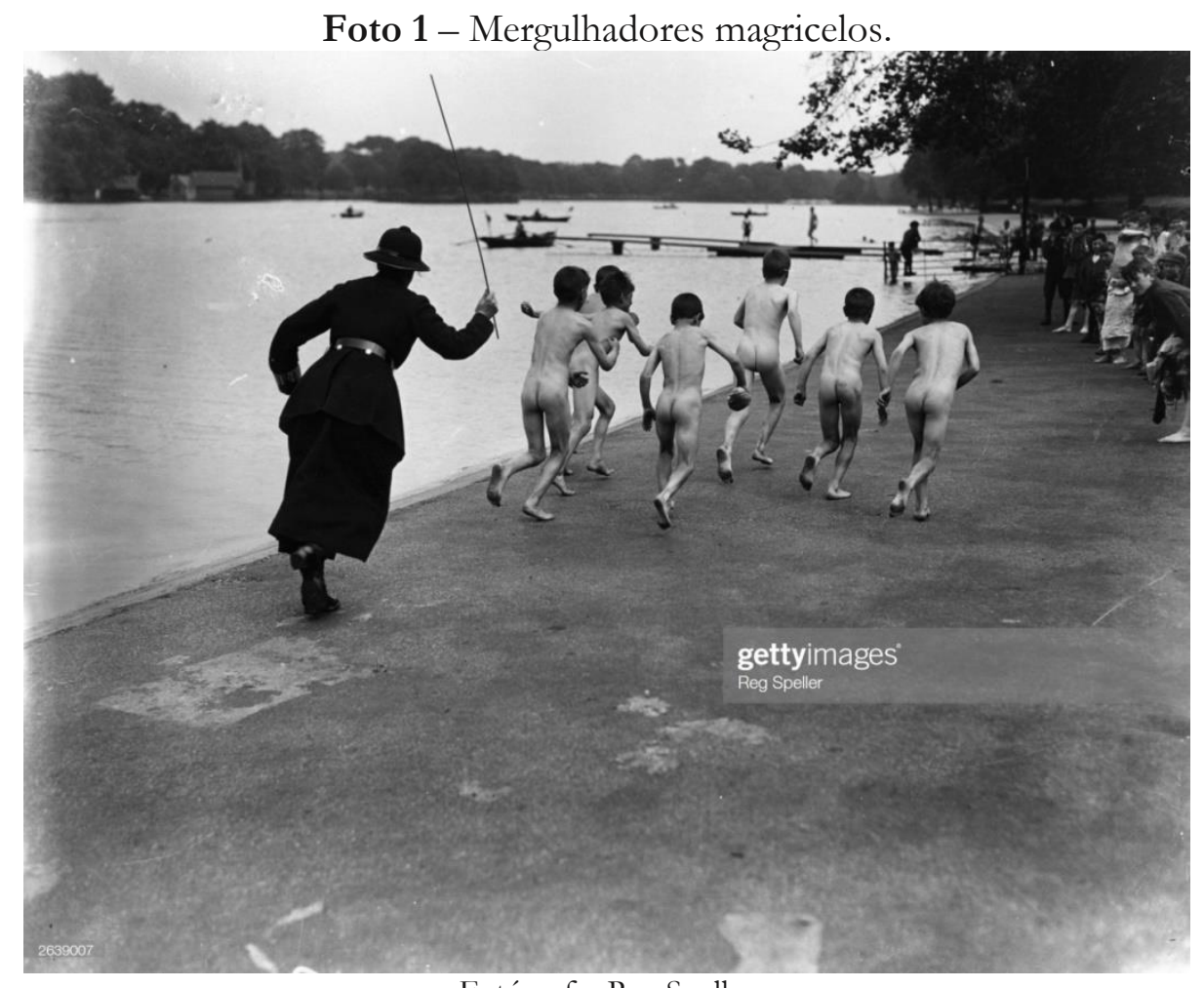

Fotógrafo: Reg Speller

Fonte: https://www.gettyimages.com.br/fotos/reg-speller.

- Olha, tio, aqui eles não devem estar rindo.

- Por que não?

- Porque eles vão apanhar, oras!

- Você não iria rir?

- De apanhar? Até parece!

- Você já fez algo assim?

- Como assim?

- Correrpelado?

- Eu já! Mas estava frio, então eu não ri muito não...

Quem ri, por fim, são as crianças.

A cena entra na conversa, inicialmente, por seu teor de fuga e medo. Ali estão visíveis, de imediato, as linhas rígidas da vida: crianças que correm, pessoas que aparentemente assistem sem ajudar, policial/professor/padre/figura autoritária que corre com claras intenções de violência. O professor insiste na pergunta: "Se vocês estivessem todos tomando banho peladas no rio. Aí de repente vem uma pessoa e grita com vocês: 'Seus moleques!’...” E, tal qual a imagem evoca, elas contam histórias de suas corridas, seus planos de sair dali em debandada. 
Há um tom institucional que parece associar a escola e a sala de aula ao controle, a um jogo político que aquieta os afetos e as possibilidades de contato-contágio entre os corpos. Esse cenário se intensifica tanto diante da fotografia que, por um momento, parece não haver solução. A escapatória, grita um menino, seria “Correr para a Lua!".

Mas seria essa a única possibilidade? Deparar-se com a vida policiada e fugir?

Se vivemos hoje uma lógica de conservadorismo exacerbado, conforme Suely Rolnik (2018) lembra, é preciso criar modos de nos desprendermos das garras da vida cafetinada. A lógica da cafetinagem é a do corpo que se acostuma a ser usado e não apenas se aquieta, como também se apaixona por quem o põe em uso contínuo. $\mathrm{Na}$ escola, a típica cena da aluna ou do aluno que, em dado momento, age como a professora ilustra bem a força do poder cafenístico. As crianças aprendem a gritar para silenciar os colegas, os representantes de sala que vigiam as outras crianças, a menina que, brincando de escolinha, se descobre brava e autoritária. Tudo em prol de um silêncio, de uma harmonia forçada, com tons de vozes abafados e afiados. A escola não pode fazer parte da rede de "traficantes de receitas de uma paz redentora" (Rolnik, 2018, p.71).

No cenário de guerra civil, o desejo obsessivo pela paz é o modo de funcionamento das forças contrainsurrecionais.

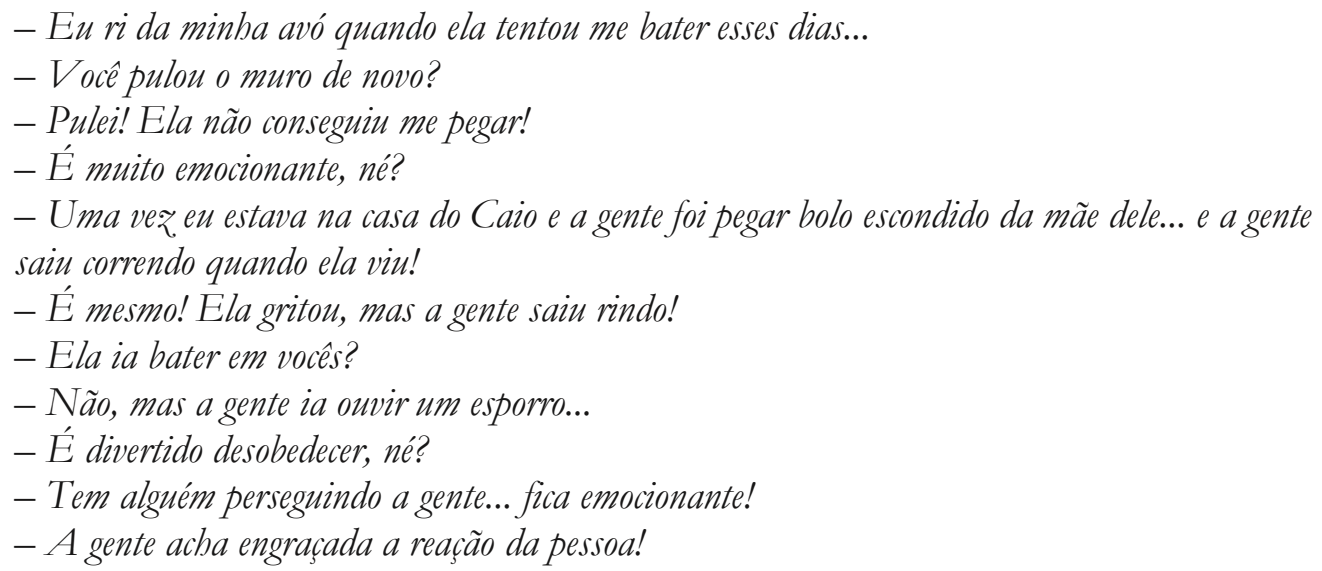

Ora, é nesse concluio entre a desordem e a alegria pela vida que, justamente, vemos as possibilidades de ruptura com as lógicas régias do poder. Se as grandes rupturas são negociáveis, no caso das pequenas rupturas as fissuras podem ser imperceptíveis, podem passar chamando a atenção de um corpo ou outro e serem apenas notas de rodapé nos grandes movimentos das linhas molares ou na visão ampla da vida. Todavia, ainda assim, ali onde as crianças descobrem um apego à vida, pelo qual a alegria é um afeto primordial (LAPOUJADE, 2017), além da paz infundada, a fotografia evoca outra leitura possível do mundo. Será que as crianças riam enquanto corriam? Será que, diante de tanto riso, o corpopoder daria cabo à ameaça prometida ou sucumbiria também à vida latente e entraria no riso? Seria o riso um gesto que transgride a rostificação e nos faz ver outros mundos possíveis? Podem as fotografias nos fazer rir e agenciar linhas de vida nos cotidianos escolares?

Foto 2 - Aulas de banho. 


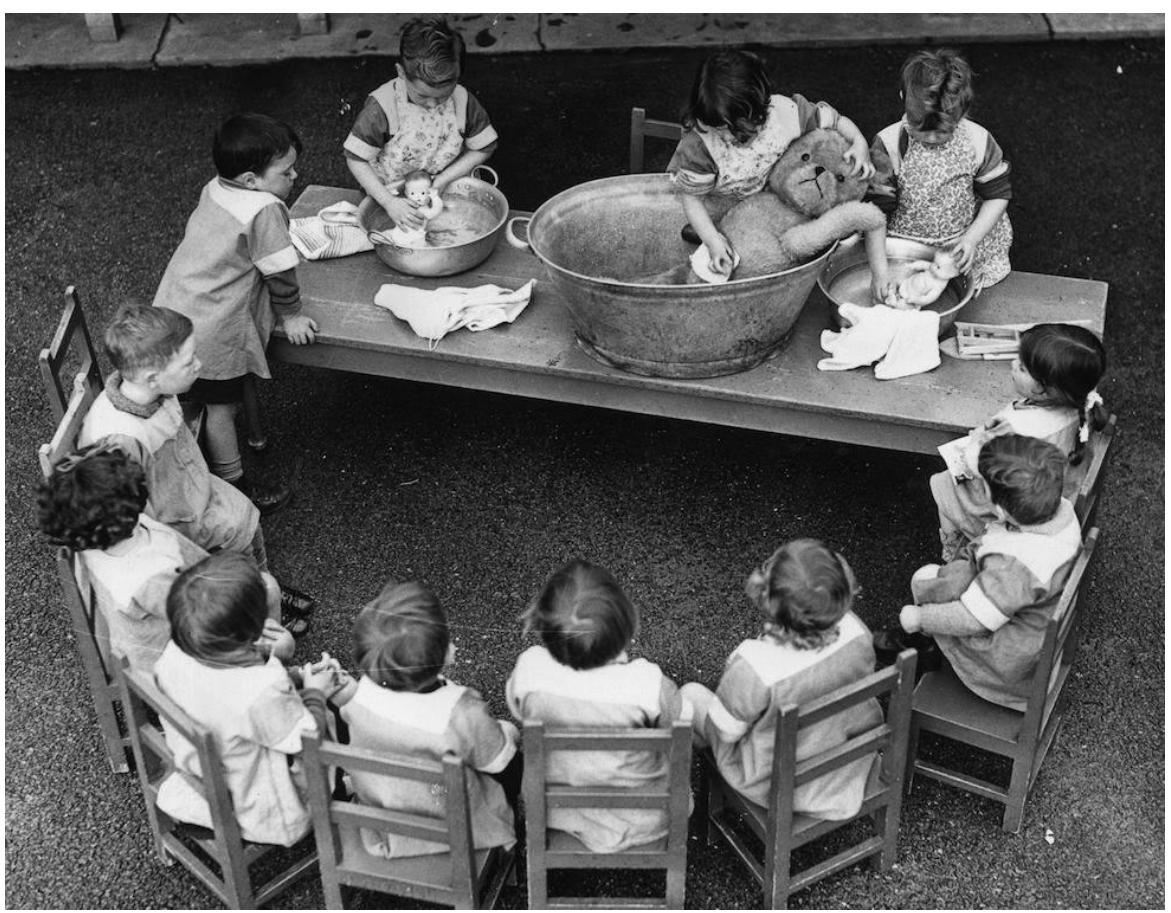

Fotógrafo: Reg Speller

Fonte: https://www.gettyimages.com.br/fotos/reg-speller.

- Nunca vi aula de banho em urso de pano... (risos)

- Pode pensar que o urso é uma criança. Né?

- A aula é sempre melhor com brincadeira e riso...

- Igual, professor, você tava brigando com a gente mais cedo, lembra?

- Por qual motivo mesmo?

- Sei lá, esqueci [risos]. Mas aí o Ryan começou a bater a cabeça dele na mesa, lembra?

- E a gente danou a rir...

- Todo mundo riu!

- A gente desobedeceu você! [risos]

- A gente tava supersério e comecou o tuc-tuc-tuc...

- Foi engraçado!

- No meio do esporro, a gente achou graça do nada!

As fotografias são imagens que agenciam tanto a ideia de vida como a de morte. Judith Butler (2015, p.103), lendo Susan Sontag, postula que os mecanismos do poder aprenderam a estruturar “[...] ativamente nossa apreensão cognitiva da guerra" a partir de fotografias que circulam socialmente. Roubando o conceito de enquadramento da fotógrafa, Butler diz que a regulação da perspectiva "[...] pode dirigir certos tipos de interpretação" (Ibidem, p.103), agenciando possíveis leituras a partir do que é visível e enunciável. Como destaca a autora: “[...] as fotografias de fato atuam sobre nós” (Ibid. p.105).

Ora, numa aproximação entre a leitura da fotografia em seu conceito de enquadramento e a indagação bergsoniana sobre o apego à vida, algumas notas são necessárias.

Primeiro, é preciso que nos demos conta de que o corpo funciona como um centro de captação de outras imagens por meio dos sentidos, ou seja, imagens visuais, olfativas, gustativas, sonoras ou táteis, ligadas entre si por conexões estabelecidas por meio de fluxos de energias/vibrações em redes. A memória mora no corpo e, em certo sentido, é o próprio corpo, como morada das imagens, que é capaz de sentir o mundo.

Segundo, as imagens são armazenadas, de acordo com Bergson (2006), recebidas e alteradas por diferentes sistemas neurais que constituem dispositivos sensório-motores que, ao receberem as sensações, as memorizam. Esse armazenamento permite que sejam realizadas algumas ações de forma automática que, com a repetição, produzirão um processo de fixação de uma imagem como imagem- 
lembrança que possibilitará, por sua vez, a realização de ações rotineiras, conduzindo, assim, a um tipo de imagem que Bergson denominará de imagem-ação, solicitada quando uma situação semelhante ocorrer - como vestir-se pela manhã e dirigir-se ao trabalho.

Desse modo, as imagens que chegam do exterior formarão uma das bases da memória, são as chamadas imagens-percepção (BERGSON, 2006). Essas imagens não conseguem absorver tudo o que nos cerca e, portanto, operam selecionando alguns aspectos e excluindo outros. Possivelmente, essas diferenças ocorram devido a certa intensidade, necessidade e motivação já instaladas em cada pessoa pela própria massa química energética que compõe o corpo/cérebro/sistema neural. No entanto, algumas imagens sofrem alterações de ordem subjetiva e, de certa forma, respondem por meio de imagens-afecção que possuem, de acordo com Bergson (2006), um sentido inverso - de dentro para fora.

Podemos, então, dizer que o pensamento, como morada e fábrica de imagens, é um fenômeno múltiplo no qual diversas forças atuam umas sobre as outras formando um campo de energia. Sendo assim, a imagem, antes que prisioneira, pode ser um vento sem fronteiras, nômade - sempre de passagem, viajante (REALI, 2017). Portanto, mesmo datada e/ou referente a uma cultura, pode manterse circulando indefinidamente, com sua capacidade de afetar e ser afetada, de modo que uma fotografia, "[...] quando viaja pelo mundo, provoca a estranha sensação de que somos nós que viajamos" (p. 42).

Assim, o nomadismo da imagem, como uma potência, só é possível pela capacidade de nos fazer viajar por meio da memória fragmentada pelos tempos e pelos espaços que nos impelem a transitar pelas culturas, pela história e pelo imaginário.

A imagem fotográfica, quando funciona em sua ampliação dos enquadramentos e das possibilidades de vida, produz entre os corpos certo grau de amizade, isto é, comporta crescimento duplo do apego à vida.

Aqui não mais falamos apenas de mudança de perspectiva. Falamos, antes, de encontros entre corpos diante de uma fotografia, de uma turma que, frente a um novo cenário fotográfico, se junta à conversa tanto para desvendar seus elementos como para traçar laços de amizade mais fortes.

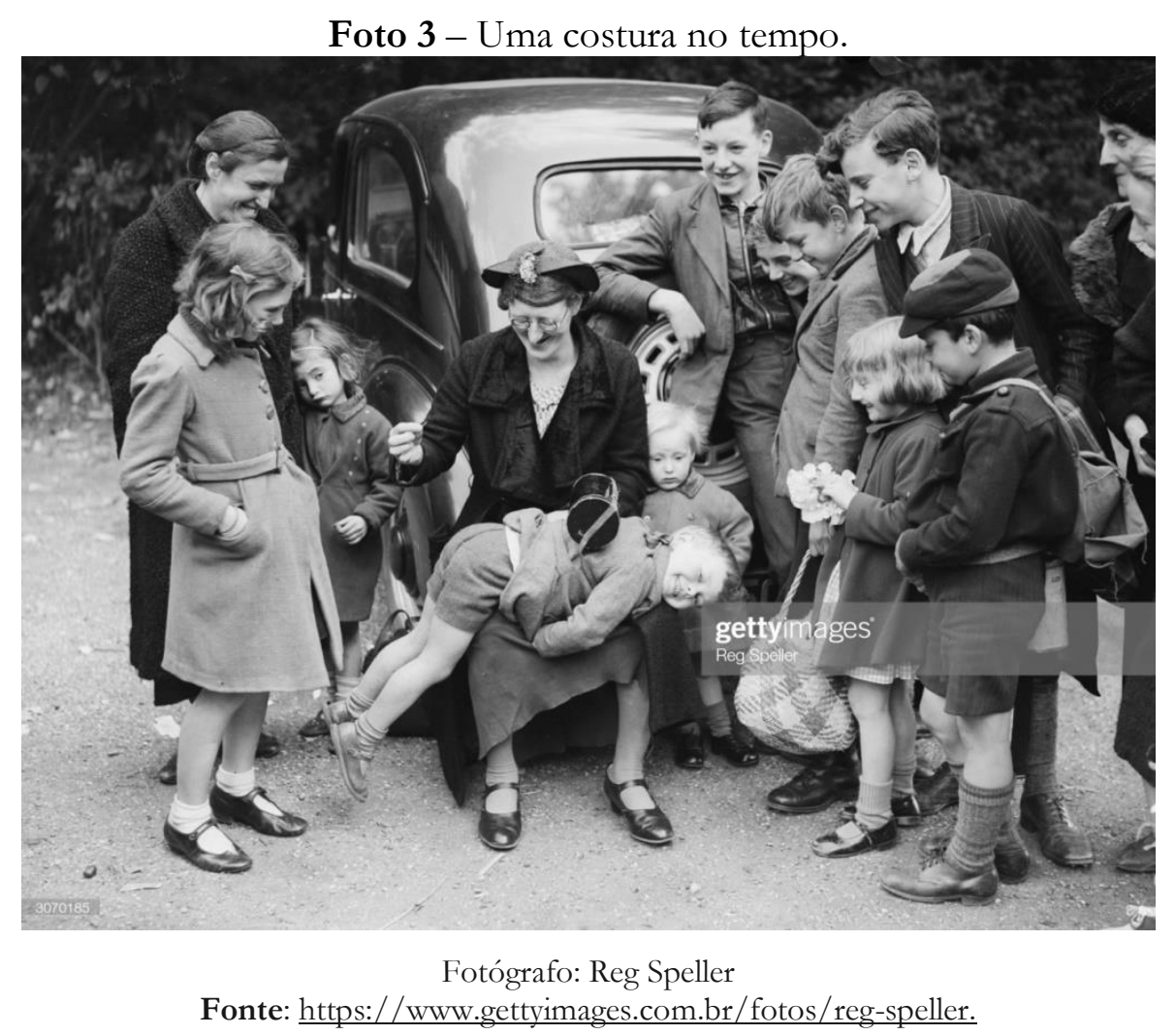

- Essa parece que o menino tá apanhando!

- Olha a bunda dele pra cima!

Educação em Revista|Belo Horizonte|v.36|e231322|2020 
- Ele está chorando?

- Não, gente, olha mais de perto... tá todo mundo rindo...

- Mas por que ele está rindo? Eu não gosto quando eu apanbo assim não...

- Você já apanhou assim de bunda pra cima no colo de alguém, Guto?

- Já, muitas vezes! É horrivel! Eu nunca ri não!

[A turma cai na gargalhada]

- Quando você quiser fugir de uns tapas, corre lá pra casa, Guto!

- Eu vou viver na sua casa, então!

- Bom que a gente se ajuda nos deveres de casa!

$-B O A ! ! !$

Eis, portanto, saídas e caminhos possíveis. Ainda que em fuga, constituição do comum, do bem que serve a todos como um ponto de produção de vida. Diante da dor do outro, crescem os afetos de cuidado, de partilha. Antonio Negri e Michael Hardt (2016) falavam que, quando tomamos uma lufada de sensibilidade e de coragem diante da situação grotesca em que nos encontramos, conseguimos romper com a lógica do privado para nos encontrarmos naquilo que nos é comum, naquilo do qual podemos desfrutar conjuntamente. $O$ homem comum é o que surge nessa situação, o corpo das alianças coletivas que ampliam a vontade de viver, o apego à vida.

No fim, descobrem que o menino deitado de bruços não estava apanhando, mas tendo seu calção remendado. Na mesma hora, a turma inteira cai na gargalhada. O riso fotográfico espalha-se por entre as faces que, minutos antes, ofereciam abrigo e cuidado ao colega. As crianças da imagem fotográfica se confundem com as crianças da sala de aula, alianças são produzidas, comuns provisórios inventados - "A gente se ajuda no dever de casa". A fotografia desdobra agenciamentos e instaura linhas de vida na escola. $\mathrm{O}$ apego à vida é expandido, visto que nas com-versas as crianças buscam forças intensivas das fotografias em relação com suas próprias vidas, não formas que se esboçam nas imagens.

Uma imagem pode, sendo assim, desencadear um bloco de intensidades com potência para produzir, conforme Deleuze e Guattari (1997, p. 19), um agenciamento do desejo, “[...] deslocando-o no tempo, desterritorializando-o, fazendo proliferar suas conexões, fazendo-o passar em outras intensidades".

Desse modo, as imagens, constituídas de potências objetivas (de fora), podem sofrer alterações profundas nas formas subjetivas (de dentro) conferindo singularidades que, compartilhadas, podem influir nos modos coletivos de ver e sentir o mundo. As imagens põem o pensamento para funcionar e podem fazê-lo estremecer. Nos movimentos do pensamento junto às fotografias, as crianças convidam a nos apegarmos à vida, deslocando nossa percepção dos esquemas sensório-motores, indicando brechas para que as linhas de vida possam rasurá-los. 
Foto 4 - Diversão antes da guerra.

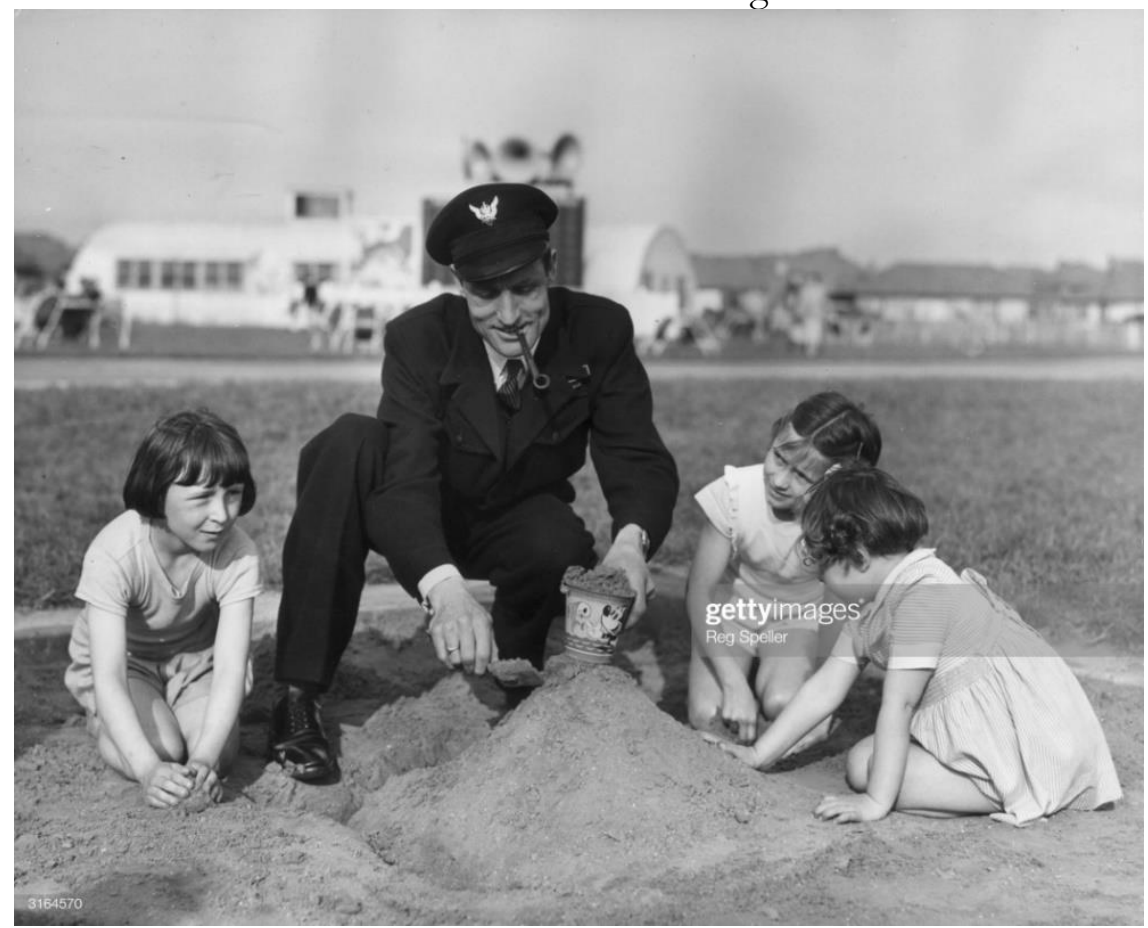

Fotógrafo: Reg Speller

Fonte: https://www.gettyimages.com.br/fotos/reg-speller.

- Nossa! Lá os policiais brincam com as crianças?

Decerto, esse é um estranhamento comum às nossas crianças. Vivemos no Brasil, em um período de política agressiva e cheia de derrotas democráticas. Vemos, diariamente, notícias sobre a polícia colocada a trabalho de uma máquina de guerra mortífera. Então, ainda que as crianças sequer saibam onde é o lá, o lá evidente da foto as surpreende. 'Os policiais podem também cuidar das pessoas?', o tom da menina parece dizer. de seus corpos.

A surpresa é coletiva, mas logo superada, suprimida e envolvida em histórias mais próximas

\section{- Aqui também pode! \\ - Pode?!}

Somos bombardeados de imagens dogmáticas de policiais pouco afeitos à vida negra, à vida periférica, à vida. Bem verdade, é claro, que o conceito de polícia pouco carrega em si afinidade com a vida. Mas, ainda assim, outras imagens são possíveis. Afinal, como os autores do Tiqqun anunciaram, o que "[...] está em jogo no confronto com o inimigo jamais é sua existência, mas sua potência" (Tiqqun, 2019, p.47). Isto é, os confrontos marcam a diminuição ou o aumento da potência de vida. Ainda que estejamos acostumados com a polícia lado a lado com a diminuição da vida, por vezes é preciso evocar seu apego à vida para que possamos criar, no mundo, outras relações entre os corpos.

Diante da fotografia de um policial montando um castelinho com duas meninas, a turma desemborca em memórias singulares de bons policiais, de brincadeiras entre os corpos-do-poder e os corpos-criança.

\section{- Antes de ontem, um policial levantou a pipa para mim!}

- No Dia das Crianças, eu estava passando assim e um policial falou pra mim: "É você mesmo que eu vou prender!’. Eu saí correndo! Ai, depois, eu voltei e ele estava lá de novo, mas estava dando presente. Ele me deu um presente! 
- Lá perto da minha casa, o policial estava dando um saquinho de lembrancinha para todo mundo.

- Eu também ganhei balas!

- É mesmo, às vezes os policiais fazem coisas legais...

- Acho que é porque eles podem ser bons...

- Tem vez que eles fazem a gente ficar feliz, né?

É possível a diversão em meio à guerra? E aqui não falamos em guerra simplesmente armamentista, mas das guerras diárias travadas diante da maquinaria capitalística que busca a todo custo nos roubar a vida, nos roubar o apego à vida. Das guerras que muitas vezes nos colocam de encontro às nossas próprias forças vitais. Talvez seja necessário questionar como fez Suely Rolnik (2018, p.39): "Como liberar a vida de sua cafetinagem?". As crianças da escola pública de Cariacica/ES nos indicam algumas aberturas: apeguem-se à vida, riam do que causa medo, compartilhem a amizade, expandam suas potências criativas. Essas aberturas não se colocam como formas, mas sim como movimentos intensivos que nos ajudam a fazer ver a possibilidade da composição de uma pluralidade de mundos.

\section{FOTOGRAFIAS DE VIDA, ABRINDO PERCEPÇÃO PARA OUTROS MUNDOS}

Se fosse o caso de escolher uma frase apta a resumir o seu trajeto como um todo, indicando ao mesmo tempo a distância que o separa da atmosfera niilista a partir dessa problemática da vida, citaríamos o trecho de Deleuze (2006a, p. 183): "Estamos em busca de uma 'vitalidade', [...] em especial de uma vitalidade política também".

Nietzsche (2005, p. 10) destaca a necessidade de uma "Grande Saúde para transitar por vários estados de corpo e realizar experimentações com o pensamento". A "Grande Saúde" não se relaciona com o ser saudável, tratando-se de não excluir a doença do campo de experimentação, pois sempre existem as linhas de expansão da vida interpenetradas às linhas de morte, forçando a abertura para a percepção de outros mundos possíveis.

Como vimos, para Deleuze e Guattari (1996), um campo social não para de ser animado por toda espécie de movimentos de descodificação e de desterritorialização que afetam "massas", segundo velocidades e andamentos diferentes. Linhas de fuga que podem gerar substituições de velhos códigos por outros: linhas de vida - linhas de morte, experimentação - prudência?

Foto 5 - Barcos de areia. 


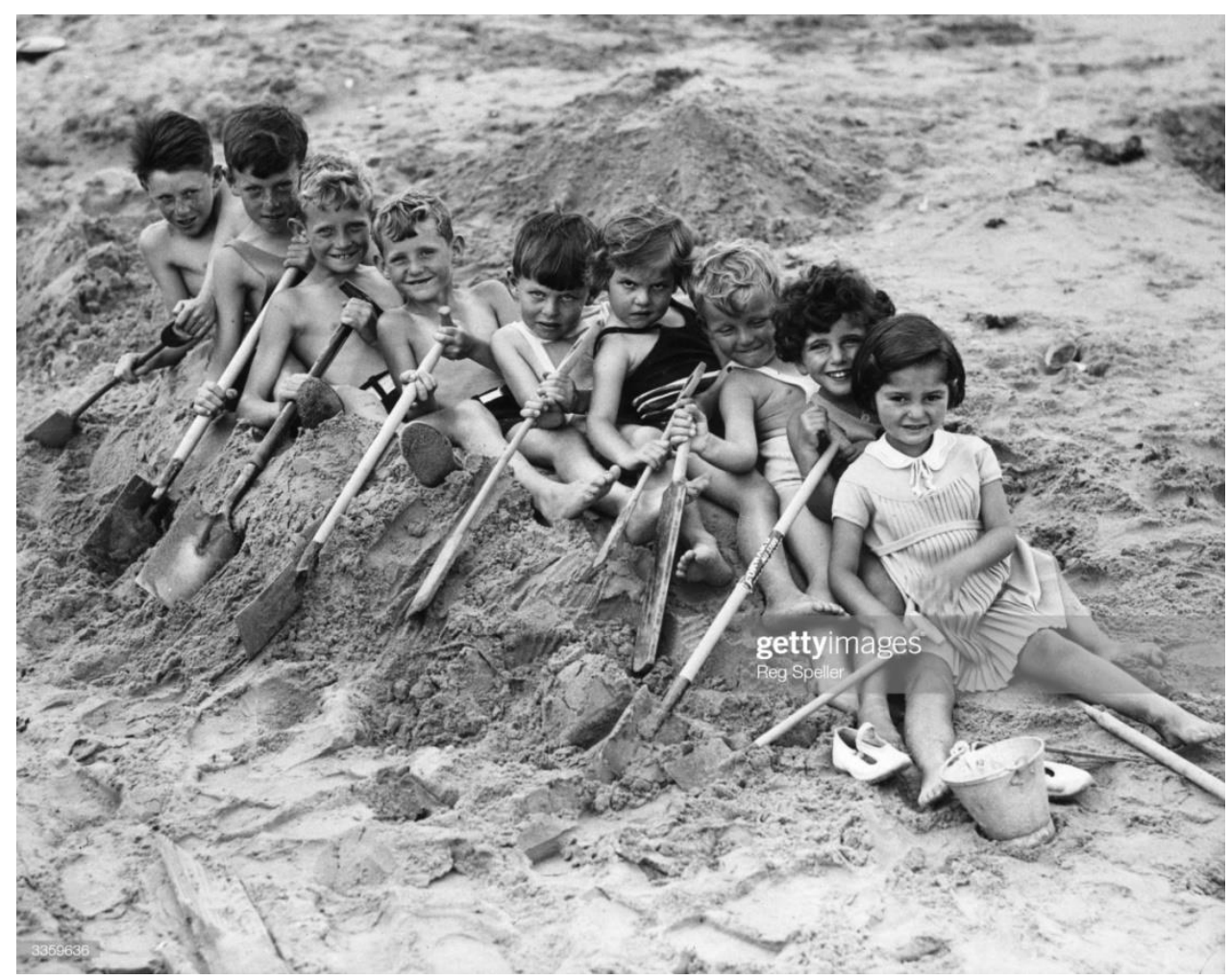

Fotógrafo: Reg Speller

Fonte: https://www.gettyimages.com.br/fotos/reg-speller.

- Eu sinto saudade de viajar do nada, de sentar no balanço e remar...

- Isso é o que eu mais faço aqui, na sala! Vou na pracinha fazer cocô, na tribo, no fundo do mar...

[A turma cai em risos]

- Ao menos ele só está falando de lugares que a gente já estudou, né?

- Pracinha fazer cocô?

- Grécia Antiga.

- Mas eles realmente estão se divertindo, né? Tem um monte de gente, dava para ter um navio de verdade...

- Um navio só de crianças! Ninguém ia mandar em ninguém!

- Eu ia mandar em vocês todos!

- A gente ia rir na sua cara!

Foto 6 - Chute alto. 


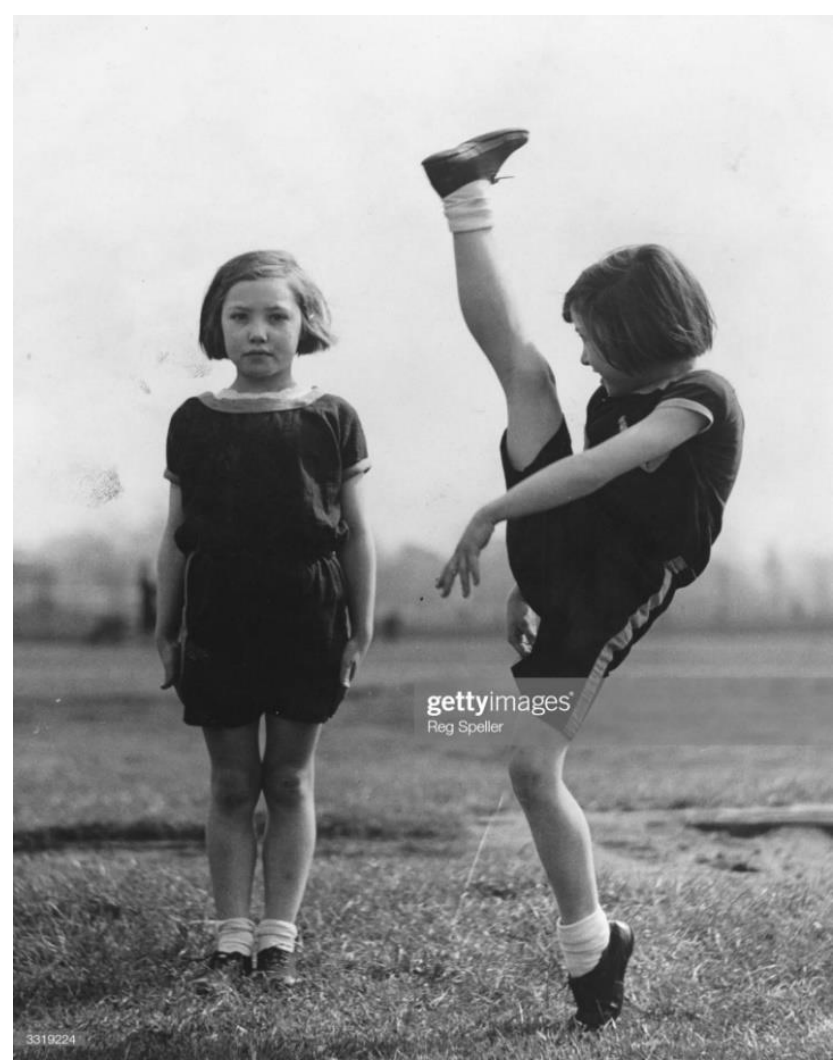

Fotógrafo: Reg Speller

Fonte: https://www.gettyimages.com.br/fotos/reg-speller.

- O engraşado dessa daqui é que uma menina tá lá toda séria... aí vem a outra e se quebra toda! Dá um chutão no ar, fica na ponta do pé...

- Ela tá morrendo de rir e a outra lá toda séria!

- Aposto que ela tá rindo da menina séria!

- Eu queria muito aprender a dançar. Eu ia dançar na escola, na rua, em todo lugar...

- É muito bom dançar...

Segundo Samain (2012, p. 21): “[...] as imagens não são bolas de sinuca”, visto que não se deslocam somente quando impactadas, empurradas. São coisas vivas que se constituem como as borboletas, as ondas do mar... Assim, partimos da concepção de que, nos processos de aprendizagem, as imagens forçam o pensamento a se movimentar. Vivem e nos fazem viver, pois "a imagem é pensante" e, sem chegar a ser um sujeito, as imagens são mais que um objeto, pois não são pessoais, são vivas e partícipes de um sistema de pensamento. "A imagem, ao fazer parte integrante de um sistema no qual circula pensamento, ela participa desse pensamento, mas, sobremaneira, participa de um circuito de pensamentos" (SAMAIN, 2012, p.31-32).

Sendo assim, parece que podemos indicar a necessidade de abertura para a aprendizagem na perspectiva do pensamento em movimento, considerando que, para que as crianças e os professores produzam as suas aprendizagens, eles necessitam que sejam oportunizados "encontros" de ideias, espaço e tempo para capturá-las e incentivos que potencializem modos coletivos de se constituírem como aprendentes no plano de consistência e de imanência da vida.

Portanto, as fotografias são concebidas como imagens capazes de ideação, ou seja, de suscitar ideias que não se confundem com o tempo e o espaço de nossa história, mas nos projetam em movimentos de pensamento, propiciando aprendizagens, problematizações e novas experimentações. 


\section{CONSIDERAÇÕES FINAIS}

\section{Pelas fotografias, a possibilidade do acontecimento: linhas de vida?}

Ao conceber a vida como acontecimento que se produz como um devir, um fazer-se, Deleuze (2006b) perspectiva o acontecimento como o que buscamos ver e, especialmente, viver nas experimentações de modo singular e, como tal, como algo que foge a uma lógica identitária na qual tudo está definido.

Acontecimento como aquilo que, ao criar, abre passagem para outros processos, dentre os quais modos de subjetividade coletiva sempre se fazendo, acontecendo, visto que "O acontecimento é imaterial, incorporal, invivível: a pura reserva" (DELEUZE; GUATTARI, 1992, p.202). Acontecimento aberto ao intempestivo da atualidade, sem categorias fixas, pelo qual os sujeitos se tornam diferentes do que são, sendo eles mesmos.

Nessa perspectiva, assume-se a ideia de que a educação é rizoma, não segmentada, fragmentária, não preocupada com a instauração de nenhuma falsa totalidade, sem pretensão de gerar modelos, propor caminhos, impor soluções.

Nas fotografias produzidas ou experimentadas cotidianamente nas escolas, ocorre a possibilidade do acontecimento. Nas superfícies das imagens quase descoladas do tempo fotografado, outros tempos, outros sentidos emergem de modo imprevisível e desestabilizador - presente e passado coincidem, pelas fotografias, atravessando e sendo atravessados por elas.

Sendo assim, a fotografia, mesmo contendo uma intenção de quem a produziu, possui "um vivido" (DELEUZE; PARNET, 2004, p.200) para além de uma determinada experiência situada num contexto e num tempo, e, então, os gestos de fotografar, olhar e pensar por elas, como afirma Wunder (2011, p.168), poderiam ser entendidos "[...] como um outro vivido, a partir de uma outra temporalidade, na lógica de uma linguagem acontecimento".

Desse modo, a fotografia produz e força o deslocamento de pensamentos e encontros incorpóreos e corpóreos de modo diferente da linguagem escrita, pois cria superfícies vibráteis, produz reencontros de tempos e espaços, reinventa o passado e ilumina o presente, podendo suscitar uma potência e uma multiplicidade de criação de sentidos ao mesmo tempo corpóreos e incorpóreos, que vivem e morrem entre a intenção do fotógrafo e a imprevisibilidade-impossibilidade de uma única interpretação própria da fotografia.

Assim, as crianças de uma escola pública da rede escolar de Cariacica, em contato com as fotografias de Reg Speller, em conversações, buscaram expressar linhas de vida em uma estética da arte de educar que vibrou na relação de seus corpos com o arco-íris de outros corpos e dos incorpóreos que pulsam em seus cotidianos como um impulso para o movimento de criação. Não arriscando dizer que esse movimento é dado pelo problema, ou seja, pela problematização e/ou invenção do problema, emergindo daí o esforço criativo, ousamos afirmar que há, nessas conversações, o coexistir do esquema dinâmico em direção às forças concretas engendradas num movimento do pensamento com suas vivências. As crianças parecem buscar alternativas e espaços criativos para fazerem acontecer os inúmeros modos possíveis de os acontecimentos se manifestarem de forma não dogmática, ou seja, em linhas de vida.

\section{REFERÊNCIAS}

BERGSON, Henri. As duas fontes da moral e da religião. Tradução de Nathanael Caixeiro. Rio de Janeiro: Zahar Editores, 1978.

BERGSON, Henri. Matéria e memória: ensaio sobre a relação do corpo com o espírito. Tradução de Paulo Neves. São Paulo: Martins Fontes, 2006. 
BUTLER, Judith. Quadros de guerra: quando a vida é passível de luto? Tradução de Sérgio Tadeu de Niemeyer Lamarão e Arnaldo Marques da Cunha. Rio de Janeiro: Civilização Brasileira, 2015.

COUTO, Mia. Contos do nascer da terra. São Paulo: Companhia das Letras, 2014.

DELEUZE, Gilles. Conversações. Tradução de Peter Pál Pelbart. Rio de Janeiro: Editora 34, 1992.

DELEUZE, Gilles. Sobre Nietzsche e a imagem pensamento. Tradução de Tomaz Tadeu e Sandra Corazza. In: DELEUZE, Gilles. A ilha deserta: e outros textos. São Paulo: Iluminuras, 2006a. p. 175183.

DELEUZE, Gilles. Lógica do sentido. Tradução de Luiz Roberto Salinas Fortes. São Paulo: Perspectiva, 2006b.

DELEUZE, Gilles; PARNET, Claire. Diálogos. Lisboa: Relógio d’Água Editores, 2004.

DELEUZE, Gilles; GUATTARI, Félix. O que é a filosofia? Tradução de Bento Prado Jr. e Alberto Muñoz. Rio de Janeiro: Editora 34, 1992.

DELEUZE, Gilles; GUATTARI, Félix. Micropolítica e segmentaridade. Tradução de Suely Rolnik. In: DELEUZE, Gilles; GUATTARI, Félix. Mil platôs: capitalismo e esquizofrenia. Rio de Janeiro: Editora 34, 1996. p. 83-115.

DELEUZE, Gilles; GUATTARI, Félix. Devir-intenso, devir-imperceptível. Tradução de Suely Rolnik. In: DELEUZE, Gilles; GUATTARI, Félix. Mil platôs: capitalismo e esquizofrenia. Rio de Janeiro: Editora 34, 1997. p. 11-114.

FOUCAULT, Michel. Vigiar e punir: nascimento da prisão. Tradução de Raquel Ramalhete. 42. ed. Petrópolis: Vozes, 2014.

FOUCAULT, Michel. A sociedade punitiva. Tradução de Ivone Benedetti. São Paulo: Editora WMF Martins Fontes, 2015. (Coleção obras de Michel Foucault).

GALLO, Silvio. Educação: entre a subjetivação e singularidade. Educação, Santa Maria, v. 35, n. 2, p. 229-244, maio/ago. 2010.

LAPOUJADE, David. Potências do tempo. Tradução de Hortência Santos Lencastre. São Paulo: n-1, 2017.

LAZZARATO, Maurizio. Signos, máquinas, subjetividades. Tradução de Paulo Domenech Oneto e Hortência Lencastre. São Paulo: Edições Sesc; n-1 edições, 2014.

NEGRI, Antonio; HARDT, Michael. Declaração: isto não é um manifesto. Tradução de Carlos Szlak.

2. Ed. São Paulo: n-1 edições, 2016.

NIETZSCHE, Friedrich. Humano, demasiado humano. Tradução de Paulo César de Souza. São Paulo: Companhia das Letras, 2005.

REALI, Noeli Gemelli. A desobediência do menor: rotas de fuga do cinema infantil. 2017. Tese. (Doutorado em Educação) - Universidade Federal de Santa Catarina, Centro de Ciências da Educação, Programa de Pós-Graduação em Educação, Florianópolis/ SC, 2017.

ROLNIK, Suely. Esferas da insurreição: notas para uma vida não cafetinada. São Paulo: n-1 edições, 2018.

SAMAIN, Etienne. As imagens não são bolas de sinuca. Como pensam as imagens. In: SAMAIN, Etienne (org.). Como pensam as imagens. Campinas: Editora da Unicamp, 2012, p. 21-36.

TIQQUN: contribuições para a guerra em curso. Tradução de Vinícius Honesko. São Paulo: n-1 edições, 2019. 
WUNDER, Alik. Fotografias, restos quase mortais. In: AMORIN, Antônio Carlos; GALLO, Silvio; OLIVEIRA JÚNIOR, Wenceslao de. (Orgs.). Conexões: Deleuze e Imagem e Pensamento e... Petrópolis: De Petrus, 2011, p. 155-176.

Submetido: $22 / 11 / 2019$

Aprovado: 26/05/2020 